\title{
Hydrogenation of imines catalysed by ruthenium(II) complexes based on lutidine-derived $\mathrm{CNC}$ pincer ligands
}

\author{
Martín Hernández-Juárez, ${ }^{a}$ Mónica Vaquero, ${ }^{b}$ Eleuterio Álvarez, ${ }^{b}$ Verónica Salazar ${ }^{* a}$ and Andrés \\ Suárez ${ }^{* b}$
}

The preparation of new $\mathrm{Ru}(\mathrm{II})$ complexes incorporating faccoordinated lutidine-derived CNC ligands is $r$ eported. These derivatives are selectively deprotonated by ${ }^{\mathrm{t}} \mathrm{BuOK}$ at one of 10 the methylene arms of the pincer, leading to catal ytically active species in the hydrogenation of imines.

Lutidine-derived pincer complexes have become a prominent class of derivatives in organometallic chemistry. ${ }^{1}$ In these complexes, pyridine dearomatisation occurs upon deprotonation 15 of the acidic $-\mathrm{CH}_{2}-$ arms, leading to species that are capable of bond activation by a metal-ligand cooperative mechanism. With respect to the flanking donor groups of the pincer, attention has been largely paid to phosphorous derivatives of type PNX ( $\mathrm{P}=$ phosphine, $\mathrm{X}=$ phosphine or hemilabile $\mathrm{N}$-donor ligand). Of 20 particular importance, group $8(\mathrm{Ru}, \mathrm{Fe})$ catalysts based on PNX ligands or their deprotonated analogues, have provided good levels of activity in the hydrogenation of a variety of polar functionalities, including ketones, esters, amides, ureas, formates, carbamates, and organic carbonates. ${ }^{2}$ In addition, replacement of ${ }_{25} \mathrm{P}$-donors in PNX-Ru complexes by more electron-donating $\mathrm{N}$ heterocyclic carbene (NHC) ligands have recently been reported. Thus, Ru pincer complexes incorporating CNN ligands with a hemilabile amine or pyridine fragment have been described. ${ }^{3,4}$ Some of these derivatives are active catalysts in the 30 hydrogenation of non-activated esters, in some cases outperforming their phosphine counterparts. ${ }^{3}$ Alternatively, examples of ruthenium complexes of $\mathrm{CNC}$ ligands are scarce, and only derivatives of type $\mathrm{Ru}(\mathrm{CNC})(\mathrm{CO}) \mathrm{ClH}$ based on meridionally coordinated $\mathrm{CNC}$ ligands with 2,6-
35 diisopropylphenyl and mesityl wingtips have been reported. ${ }^{4}$

In this communication, we present the synthesis and structural characterisation of new $\mathrm{Ru}$ complexes $\mathbf{3}$ containing faccoordinated bis- $N$-heterocyclic carbene $\mathrm{CNC}$ ligands. Furthermore, application of these complexes in the hydrogenation 40 of various imines is reported.

Synthesis of new bis-imidazolium salts 1 have been effected by refluxing of acetonitrile or THF solutions of the corresponding 2,6-bis(halomethyl)pyridine and 1 -substituted $1 H$-imidazole in a $1: 2$ ratio. $^{5}$ Initial experiments directed to the synthesis of 45 ruthenium complexes incorporating $\mathrm{CNC}$ ligands derived from $\mathbf{1}$ were performed by reaction of the imidazolium salt $\mathbf{1 a}(\mathbf{B r})$ with different $\mathrm{Ru}$ precursors $\left(\mathrm{RuHCl}\left(\mathrm{PPh}_{3}\right)_{3}, \quad \mathrm{RuCl}_{2}\left(\mathrm{PPh}_{3}\right)_{3}\right.$, $\left.\mathrm{RuHCl}(\mathrm{CO})\left(\mathrm{PPh}_{3}\right)_{3}, \mathrm{RuH}_{2}(\mathrm{CO})\left(\mathrm{PPh}_{3}\right)_{3}\right)$ in the presence of base. This approach, however, leads to inseparable mixture of products, 50 and an alternative procedure based on $\mathrm{N}$-heterocyclic carbene transfer with Ag-NHC complexes was considered. ${ }^{6}$ Reaction of bis-imidazolium salts 1 with 1 equiv of $\mathrm{Ag}_{2} \mathrm{O}$ in $\mathrm{CH}_{2} \mathrm{Cl}_{2}$ at room temperature results in the clean formation of bimetallic silver complexes 2 (Scheme 1). ${ }^{5}$ These derivatives were found adequate ${ }_{55}$ for $\mathrm{CNC}$ ligand transfer to $\mathrm{RuHCl}(\mathrm{CO})\left(\mathrm{PPh}_{3}\right)_{3}$. Thus, complexes $\mathbf{3 a}(\mathbf{C l})$ and $\mathbf{3 b}(\mathbf{C l})$ were conveniently prepared from the appropriate silver reagent 2 and $\mathrm{RuHCl}(\mathrm{CO})\left(\mathrm{PPh}_{3}\right)_{3}$ in THF at 55 ${ }^{\circ} \mathrm{C}$. Similarly, complexes $\mathbf{3 a}\left(\mathbf{B F}_{4}\right)$ and $\mathbf{3 c}(\mathbf{B r})$ were synthesised by reaction of the corresponding bromide derivatives $\mathbf{2 a}(\mathbf{B r})$ and $\left.{ }_{60} \mathbf{2 c ( B r}\right)$ with $\mathrm{RuHCl}(\mathrm{CO})\left(\mathrm{PPh}_{3}\right)_{3}$ followed by treatment with $\mathrm{NaBF}_{4}$ and $\mathrm{NaBr}$, respectively. Finally, synthesis of 3,5-xilylsubstituted $3 \mathbf{d}(\mathbf{C l})$ was more conveniently carried out in $\mathrm{CH}_{2} \mathrm{Cl}_{2}$ at room temperature.

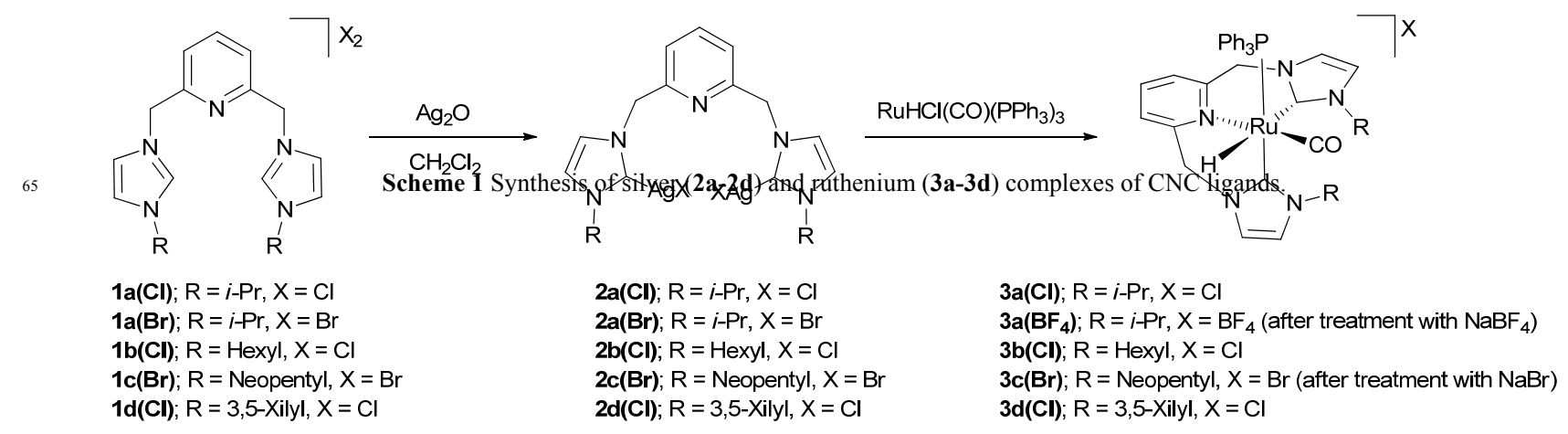


Complexes 3 have been fully characterized, and their NMR data reveal very similar features for all complexes of the series. For example, the ${ }^{31} \mathrm{P}\left\{{ }^{1} \mathrm{H}\right\}$ NMR spectrum of $\mathbf{3 a}(\mathbf{C l})$ shows a singlet at 42.4 ppm. Furthermore, ${ }^{1} \mathrm{H}$ and ${ }^{13} \mathrm{C}\left\{{ }^{1} \mathrm{H}\right\}$ NMR spectra 5 reflect the non-equivalence of the two halves of the $\mathrm{CNC}$ ligand. In the ${ }^{1} \mathrm{H}$ NMR spectrum of $\mathbf{3 a}(\mathbf{C l})$, the hydrido ligand gives rise to a doublet at $-7.38 \mathrm{ppm}\left(J_{\mathrm{HP}}=30.4 \mathrm{~Hz}\right)$, while methylene protons of the $\mathrm{CNC}$ ligand produce four different doublet signals in the range 4.1-5.7 ppm. The ${ }^{13} \mathrm{C}\left\{{ }^{1} \mathrm{H}\right\}$ NMR spectrum shows 10 one doublet signal for each $\mathrm{C}^{2}$ carbon atom of the NHC fragment at $180.4\left(J_{\mathrm{CP}}=81 \mathrm{~Hz}\right.$, trans to $\left.\mathrm{PPh}_{3}\right)$ and $187.9\left(J_{\mathrm{CP}}=8 \mathrm{~Hz}\right.$, trans to $\mathrm{H})$, whereas the carbonyl ligand signal appears at $209 \mathrm{ppm}$ as a doublet $\left(J_{\mathrm{CP}}=15 \mathrm{~Hz}\right)$. These data are consistent with an unprecedented $f a c$ coordination mode of the $\mathrm{CNC}$ ligand, in 15 which one NHC fragment is placed trans to the hydrido ligand and the other is trans to $\mathrm{PPh}_{3}{ }^{7}$ The $\mathrm{CO}$ stretch bands in the IR spectrum of complexes 3 appears in the range 1919-1934 $\mathrm{cm}^{-1}$.

Further confirmation of the structure of coordinated CNC ligands in complexes $\mathbf{3}$ was obtained from a study by single20 crystal X-ray diffraction of $\mathbf{3} \mathbf{a}\left(\mathbf{B F}_{\mathbf{4}}\right)$ (Figure 2). This complex, in the solid state, consists of a distorted octahedral structure containing the $\mathrm{CNC}$ pincer coordinated in a fac configuration $\left(\mathrm{C}^{2}(\mathrm{NHC})-\mathrm{Ru}-\mathrm{C}^{2}(\mathrm{NHC})=101.3(8)^{\circ}\right)$, while the $\mathrm{CO}$ is placed trans to the pyridine nitrogen atom of the pincer system. Complex ${ }_{25} \mathbf{3} \mathbf{a}\left(\mathbf{B F}_{4}\right)$ is chiral by virtue of the stereogenic center present in the $\mathrm{Ru}$ atom. Both six-membered ruthenacycles involving the NHC and pyridine donors adopt boat-like conformations defined by dihedral angles $\mathrm{C}(5)-\mathrm{N}(1)-\mathrm{Ru}(1)-\mathrm{C}(14) \quad$ and $\mathrm{C}(1)-\mathrm{N}(1)-\mathrm{Ru}(1)-\mathrm{C}(8) \quad$ of $25.9(15)^{\circ}$ and $-47.3(15)^{\mathrm{o}}$, 30 respectively. In addition, $\mathrm{Ru}-\mathrm{C}^{2}(\mathrm{NHC})$ distances $(2.117 \AA$, trans to $\mathrm{H} ; 2.084 \AA$, trans to $\mathrm{PPh}_{3}$ ) fall in the range of previously reported values, ${ }^{3}$ and reflects the expected larger trans influence of the hydrido ligand.

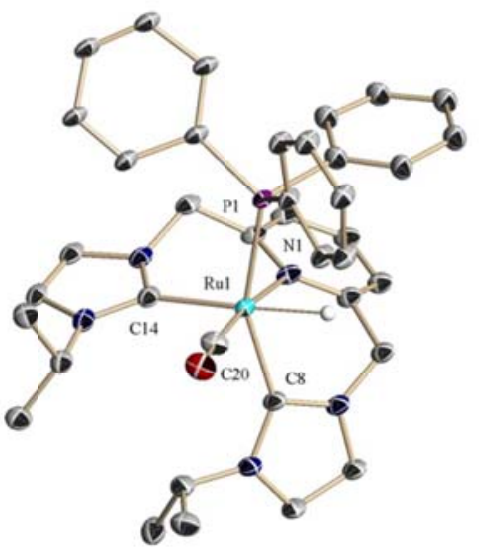

35 Fig. 2 ORTEP drawing at $30 \%$ ellipsoid probability of the cationic component of complex $\mathbf{3 a}\left(\mathbf{B F}_{4}\right)$. Hydrogen atoms, except for hydride ligand, have been omitted for clarity. Selected bond lengths $[\AA]$ and angles [ $\left.{ }^{\circ}\right]$ : $\mathrm{Ru}(1)-\mathrm{N}(1) 2.233(16) ; \mathrm{Ru}(1)-\mathrm{C}(8) 2.084(19) ; \mathrm{Ru}(1)-\mathrm{C}(14)$ 2.117(19); $\mathrm{Ru}(1)-\mathrm{C}(20) \quad 1.79(2) ; \quad \mathrm{C}(8)-\mathrm{Ru}(1)-\mathrm{C}(14) \quad 101.3(8)$; ${ }_{40} \mathrm{~N}(1)-\mathrm{Ru}(1)-\mathrm{C}(20) \quad 173.3(8) ; \quad \mathrm{C}(8)-\mathrm{Ru}(1)-\mathrm{N}(1) \quad 80.8(7)$ $\mathrm{C}(14)-\mathrm{Ru}(1)-\mathrm{N}(1) \quad 87.7(7) ; \quad \mathrm{C}(8)-\mathrm{Ru}(1)-\mathrm{C}(20) \quad 92.6(9)$ $\mathrm{C}(14)-\mathrm{Ru}(1)-\mathrm{C}(20)$ 94.9(9); N(1)-Ru(1)-P(1) 92.1(4).

Treatment of complexes $\mathbf{3 a}(\mathbf{C l})$ and $\mathbf{3 d}(\mathbf{C l})$ with ${ }^{\mathrm{t}} \mathrm{BuOK}$ in
THF $-d_{8}$ cleanly gives derivatives $4 \mathbf{a}$ and $\mathbf{4 d}$, respectively 140 (Scheme 2). These compounds are rather unstable and decompose in solution at room temperature in a few hours. In the ${ }^{31} \mathrm{P}\left\{{ }^{1} \mathrm{H}\right\}$ NMR spectrum, complex $4 \mathbf{a}$ exhibits a singlet at $47.9 \mathrm{ppm}$. The hydrido ligand gives rise to a doublet at $-7.32 \mathrm{ppm}\left(J_{\mathrm{HP}}=23.0\right.$ $\mathrm{Hz}$ ) in the ${ }^{1} \mathrm{H}$ NMR spectrum, whille the vinylic proton appears as 145 a singlet at $4.77 \mathrm{ppm}$. More interestingly, the pyridine protons signals show significant upfield shifts as a consequence of pyridine dearomatisation, appearing in the range $4.6-5.5 \mathrm{ppm}$. In the ${ }^{13} \mathrm{C}\left\{{ }^{1} \mathrm{H}\right\}$ NMR spectrum, the carbonyl ligand produces a doublet at $210.6 \mathrm{ppm}\left(J_{\mathrm{CP}}=14 \mathrm{~Hz}\right)$, and the $\mathrm{C}^{2}-\mathrm{NHC}$ carbon 150 atoms appear as doublets at 181.2 $\mathrm{ppm}\left(J_{\mathrm{CP}}=9 \mathrm{~Hz}\right)$ and 187.4 $\operatorname{ppm}\left(J_{\mathrm{CP}}=96 \mathrm{~Hz}\right)$. Similar spectroscopic data have been found for $4 \mathbf{d}$. These values are in accord with a facially coordinated $\mathrm{CNC}$ ligand. In addition, intense cross-peak signals between the vinylic proton and the $\mathrm{C}^{2}$ of the $\mathrm{NHC}$ fragment coordinated cis to ${ }_{155} \mathrm{PPh}_{3}$ have been observed in the ${ }^{1} \mathrm{H}-{ }^{13} \mathrm{C}$ HMBC experiment, indicative of a selective deprotonation of the methylene arm of the NHC fragment coordinated trans to the hydride.

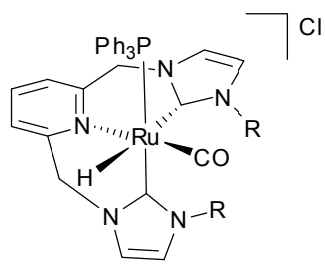

$3 a(C l), 3 d(C l)$

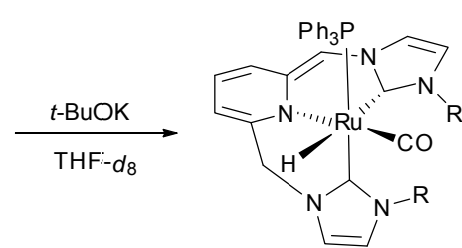

$4 a, 4 d$
Scheme 2 Synthesis of $\mathbf{4 a}$ and $\mathbf{4 d}$.

150 The catalytic behaviour of complexes $\mathbf{3}$ in the hydrogenation of imines has been examined. In the presence of ${ }^{t} \mathrm{BuOK}$, complexes 3 catalyse the hydrogenation of $N$-benzylideneaniline under 5 bar of $\mathrm{H}_{2}$ at $70{ }^{\circ} \mathrm{C}$ in 2-methyltetrahydrofuran, using a $\mathrm{S} / \mathrm{C} / \mathrm{B}$ ratio of $1000 / 1 / 10$ (Table 1 , entries $1-4$ ). In the series, 155 complex $3 \mathbf{b}(\mathbf{C l})$ leads to the more active catalyst. Next, we sought to probe the scope of the reaction, and thus various $N$-aryl and $\mathrm{N}$-alkyl aldimines were examined. Substrates bearing electron-releasing substituents are also reduced with high activities (entry 5), whereas the presence of strongly electron160 withdrawing substituents in both aryl groups significantly reduces the reactivity (entries 6 and 7). Also, a $N$-benzyl aldimine was hydrogenated more slowly than the analogous $N$-phenyl imine (entry 8). Finally, complex $\mathbf{3 b}(\mathbf{C l})$ also catalyses the hydrogenation of a series of $N$-aryl ketimines with high turnover 165 frequencies, independently of the electronic characteristics of the aryl substituents (entries 9-15).

\section{Conclusions}

In summary, new ruthenium complexes 3 incorporating neutral $\mathrm{CNC}$ ligands have been prepared and structurally characterised. ${ }_{130}$ Contrary to previously observed mer geometry of coordinated CNC ligands, complexes 3 exhibit a $f a c$ coordination mode for the pincer, what might be relevant for the design of novel chiral catalysts based on structurally similar terdentate ligands. Upon reaction with ${ }^{t} \mathrm{BuOK}$, selective deprotonation at one of the 135 methylene arms of the $\mathrm{CNC}$ ligand occurs, leading to dearomatisation of the pyridine ring. Finally, complexes 3 
provide significant levels of catalytic activity in the hydrogenation of a variety of imines. This represents, to the best of our knowledge, the first application of $\mathrm{Ru}$ complexes containing dearomatised lutidine-derived pincer ligands in the 5 important hydrogenation of $\mathrm{C}=\mathrm{N}$ bonds. ${ }^{8}$ Investigations directed to obtain further insight into the mechanism of the imine hydrogenation, as well as the use of complexes $\mathbf{3}$ in other catalytic processes are being pursued.

Prof. F. Sánchez (IQOG-CSIC) and Dr. A. Pizzano are thanked 10 for helpful discussions. Financial support (FEDER contribution) from the Spanish MINECO (CTQ2009-11867), ConsoliderIngenio 2010 (CSD2007-00006), and the Junta de Andalucía (2008/FQM-3830, 2009/FQM-4832) is gratefully acknowledged. M. H. J. thanks CONACYT for a fellowship (214238).

\section{${ }_{15}$ Notes and references}

${ }^{a}$ Centro de Investigaciones Químicas, Universidad Autónoma del Estado de Hidalgo, Carretera Pachuca-Tulancingo Km 4.5, 42184, Mineral de la Reforma, Hidalgo, Mexico. Fax: $52771717200 x 6502$; Tel: 52771 1550933; E-mail: salazar@uaeh.edu.mx

${ }_{20}{ }^{b}$ Instituto de Investigaciones Químicas (IIQ), Consejo Superior de Investigaciones Cientificas and Universidad de Sevilla, Avda Américo Vespucio no. 49, 41092, Sevilla, Spain. Fax: 34 954460565; Tel: 34 954489556; E-mail: andres.suarez@iiq.csic.es

$\dagger$ Electronic Supplementary Information (ESI) available: Representative 25 experimental procedures, compound characterisation, crystalographic information for $\mathbf{3 a}\left(\mathbf{B F}_{4}\right)$ (CCDC reference 894892). See DOI: $10.1039 / \mathrm{b} 000000 \mathrm{x} /$

1 (a) J. I. van der Vlugt and J. N. H. Reek, Angew. Chem. Int. Ed., 30 2009, 48, 8832-8846; (b) C. Gunanathan and D. Milstein, Acc. Chem. Res., 2011, 44, 588-602.

2 (a) J. Zhang, G. Leitus, Y. Ben-David and D. Milstein, Angew. Chem. Int. Ed., 2006, 45, 1113-1115; (b) E. Balaraman, B. Gnanaprakasam, L. J. W. Shimon and D. Milstein, J. Am. Chem.

35 Soc., 2010, 132, 16756-16758; (c) C. A. Huff and M. S. Sanford, J. Am. Chem. Soc., 2010, 133, 18122-18125; (d) E. Balaraman, Y. BenDavid and D. Milstein, Angew. Chem. Int. Ed., 2011, 50, 11702-11705; (e) E. Balaraman, C. Gunanathan, J. Zhang, L. J. W. Shimon and D. Milstein, Nature Chem., 2011, 3, 609-614; $(f)$ J.

40 Zhang, E. Balaraman, G. Leitus and D. Milstein, Organometallics, 2011, 30, 5716-5724; $(g)$ R. Langer, G. Leitus, Y. Ben-David and D. Milstein, Angew. Chem. Int. Ed., 2011, 50, 2120-2124; (h) R. Langer, M. A. Iron, L. Konstantinovski, Y. Diskin-Posner, G. Leitus, Y. Ben-David and D. Milstein, Chem. Eur. J., 2012, 18, 7196-7209.

453 (a) Y. Sun, C. Koehler, R. Tan, V. T. Annibale and D. Song, Chem. Commun., 2011, 47, 8349-8351; (b) E. Fogler, E. Balaraman, Y. Ben-David, G. Leitus, L. J. W. Shimon and D. Milstein, Organometallics, 2011, 30, 3826-3833.

4 C. del Pozo, M. Iglesias and F. Sánchez, Organometallics, 2011, 30, $50 \quad 2180-2188$

5 (a) A. A. D. Tulloch, A. A. Danopoulos, G. J. Tizzard, S. J. Coles, M. B. Hursthouse, R. S. Hay-Motherwell and W. B. Motherwell, Chem. Commun., 2001, 1270-1271; (b) R. S. Simons, P. Custer, C. A. Tessier and W. J. Youngs, Organometallics, 2003, 22, 1979-1982; (c) A. A. Danopoulos, A. A. D. Tulloch, S. Winston, G. Eastham and M. B. Hursthouse, Dalton Trans., 2003, 1009-1015; (d) D. J. Nielsen, K. J. Cavell, B. W. Skelton and A. H. White, Inorg. Chim. Acta, 2006, 359, 1855-1869; (e) K. Inamoto, J. Kuroda, E. Kwon, K. Hiroya, T. Doi, J. Organomet. Chem., 2009, 694, 389-396.

606 I. J. B. Lin and C. S. Vasam, Coord. Chem. Rev., 2007, 251, 642-670.

7 Only mer coordination of $\mathrm{CNC}$ ligands has been reported: $(a)$ ref. 5; (b) D. Pugh and A. A. Danopoulos, Coord. Chem. Rev., 2007, 251 610-641, and cited references; (c) D. Serra, P. Cao, J. Cabrera, R.

65 Padilla, F. Rominger and M. Limbach, Organometallics, 2011, 30,
1885-1895; (d) J. Dinda, S. Liatard, J. Chauvin, D. Jouvenot and F. Loiseau, Dalton Trans., 2001, 40, 3683-3688.

8 C. Claver and E. Fernández, in Modern Reduction Methods, ed. P. G. Andersson and I. J. Munslow, Wiley-VCH, Weinheim, 2008, ch. 10.

70 Table 1 Hydrogenation of imines catalysed by ruthenium complexes $\mathbf{3}^{a}$

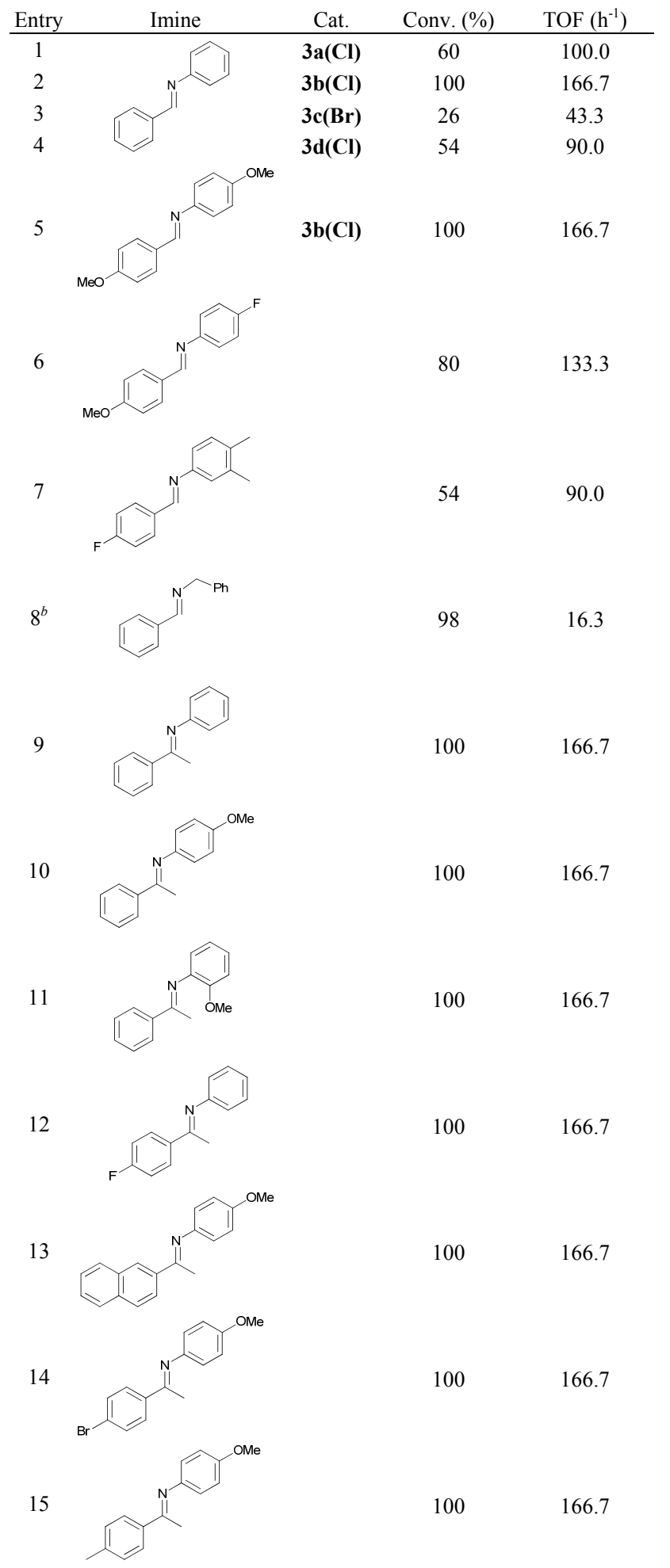

${ }^{a}$ Reaction conditions, unless otherwise noted: 5 atm $\mathrm{H}_{2}, 70{ }^{\circ} \mathrm{C}$, 2methyltetrahydrofuran, $\mathrm{S} / \mathrm{C} / \mathrm{B}=1000 / 1 / 10$, base: ${ }^{\mathrm{t}} \mathrm{BuOK}, 6 \mathrm{~h}$. $[\mathrm{S}]=1.4 \mathrm{M}$. Conversion was determined by ${ }^{1} \mathrm{H}$ NMR. TOF values as calculated from conversion. ${ }^{b} \mathrm{~S} / \mathrm{C} / \mathrm{B}=100 / 1 / 10$. 